\title{
The response of drinking water related endemic arsenism on water quality improvement
}

\author{
LINSHENG YANG ${ }^{12}$ \\ ${ }^{1}$ Key Laboratory of Land Surface Pattern and Simulation, \\ Institute of Geographic Sciences and Natural Resources \\ Research, Chinese Academy of Sciences \\ ${ }^{2}$ Collage of Resources and Environment, University of Chinese \\ Academy of Sciences, Beijing, People's Republic of China
}

Water quality improvement is the primary pathway to prevent arsenism. The arsenic metabolism and arsenism caused by drinking water after water quality improvement were investigated in the present study. The results indicated that the mean concentration of arsenic in nail was decreased from $12.30 \mathrm{mg} / \mathrm{kg}$ to 0.6 $\mathrm{mg} / \mathrm{kg}$. The mean urinary contents of iAs, MMA and DMA dropped to $1.88,2.32$ and $18.6 \mu \mathrm{g} / \mathrm{L}$, respectively. The values varied slightly with the that of the control cohort. Moreover, the arsenic methylation capacity was significantly increased. The study group aged 31-50 years had the highest increase in primary arsenic methylation capacity. After water quality improvement, the degree of skin lesions (hyperkeratosis, pigmentation and depigmentation) for some cases were recovered or improved, and that for some cases were aggravated, while some health cases were diagnosed with skin lesions after water quality improvement. It can be concluded that urinary arsenic species content and arsenic methylation capacity increased to the levels of the control cohort after water quality improvement. An increase in primary arsenic methylation capacity may be a burden on the secondary arsenic methylation capacity. The effects of arsenic methylation capacity impacted on skin lesions might be decreased with longer arsenic exposure duration. 